\title{
Nutrição e fitoterapia popular: uma avaliação do conhecimento e uso de plantas medicinais em adultos participantes da pastoral da saúde
}

\author{
Nutrition and popular phytotherapy: an assessment of the knowledge and use of medicinal \\ plants in adults participating in the pastoral health \\ Nutrición y fitoterapia popular: evaluación del conocimiento y uso de plantas medicinales \\ en adultos integrantes de la pastoral de la salud
}

Juliana Gonçalves de Oliveira ${ }^{1 *}$, Cássia Regina Bruno Nascimento ${ }^{1}$, Isabel Fernandes de Souza1.

\section{RESUMO}

Objetivo: Avaliar o conhecimento e uso de plantas medicinais e fitoterápicos em adultos participantes da pastoral da saúde de uma cidade do Paraná, e verificar alterações de consumo relacionados ao contágio do vírus SARS-CoV-2. Métodos: Trata-se de um estudo observacional-exploratório qualitativo, organizado através de um roteiro de entrevista semiestruturada. O recrutamento dos participantes se deu pela rede Facebook com dados transcritos e analisados segundo a análise de conteúdo. Resultados: Fizeram parte do estudo 10 participantes, entre 32 e 60 anos, com prevalência do sexo feminino e origem das práticas através do cuidado com a mãe. Houve somente cinco espécies com conhecimento popular diferente do científico. Quanto ao comportamento em relação ao isolamento social, relataram somente em caso de diagnóstico positivo, o uso indiscriminado de chás antigripais com plantas medicinais dentro de seu conhecimento. Conclusão: A maioria dos saberes e das práticas foram adquiridas no ambiente familiar com a mulher como a principal detentora e difusora desse conhecimento, no entanto, faz-se necessário melhor conhecimento quanto a formas de preparo em plantas tenras para eficaz extração dos princípios ativos. Pacientes expostos ao vírus causador do COVID-19 podem apresentar comportamento inadequado quanto ao consumo de plantas medicinais induzidos pelo medo.

Palavras-chave: Nutrição, Fitoterapia, Plantas medicinais, COVID-19.

\begin{abstract}
Objective: To assess the knowledge and use of medicinal plants and herbal medicines in adults of the pastoral health of a city in Paraná, and assess changes in consumption related to the spread of the SARS-CoV-2 virus. Methods: A qualitative observational exploratory study in the format of a semi-structured interview script. Participants were recruited through the Facebook network and data were transcribed and analyzed according to content analysis. Results: Ten subjects aged 32-60 years participated in the study, with a prevalence of females and the origin of practices was through mothers' care with their children. In only five species popular knowledge was different from scientific knowledge. Regarding behaviors of social isolation and use of anti-flu teas, participants reported they would use medicinal plants without medical supervision only in case of positive diagnosis. Conclusion: Most knowledge and practices were acquired in the family environment, and women were the main owners of this knowledge and responsible for spreading it. Better knowledge about the form of preparation of tender plants is needed for the effective extraction of their active principles. Patients exposed to the SARS-CoV-2 virus may exhibit inappropriate behavior regarding the consumption of medicinal plants induced by fear.
\end{abstract}

Keywords: Nutrition, Fitotherapy, Medicinal plants, COVID-19.

${ }^{1}$ Centro Universitário União das Américas (UNIAMÉRICA), Foz do Iguaçu - PR.

*E-mail: julianagoncalvesdeoliveira@outlook.com 


\section{RESUMEN}

Objetivo: Evaluar los conocimientos, aplicaciones de plantas medicinales y fitoterápicos en adultos participantes de la pastoral de Salud de una ciudad en Paraná, y verificar los cambios y aplicaciones en el consumo relacionadas a la propagación del virus SARS-CoV-2. Métodos: Se trata de un estudio observacional-exploratorio cualitativo, organizado a través de un guión de entrevista semiestructurado. El reclutamiento de los participantes se hizo por la red Facebook con datos transcritos y analizados según análisis de contenido. Resultados: Han participado 10 personas, con una mayor presencia de mujeres con conocimientos y aplicaciones adquiridos de la figura materna a través del cuidado. Se distinguen cinco especies de plantas conocidas popularmente que difieren a los conocimientos científicos. En cuanto al comportamiento relacionado al aislamiento social, relatan sólo en caso de diagnóstico positivo, el uso indiscriminado de tés antigripales con plantas medicinales. Conclusión: La mayoría de los conocimientos y prácticas se adquirieron en el ámbito familiar con la mujer como principal poseedor y difusora de este conocimiento, sin embargo, es necesario tener un mejor conocimiento de cómo prepararse en plantas tiernas. Los pacientes expuestos al virus que causa COVID-19 pueden exhibir un comportamiento inapropiado con respecto al consumo de plantas medicinales.

Palabras clave: Nutrición, Fitoterapia, Plantas medicinales, COVID-19.

\section{INTRODUÇÃO}

A fitoterapia é o método mais antigo para tratamento de doenças, refere-se ao uso das plantas medicinais com comprovação através de estudo baseado em evidências científicas. Abrange desde a identificação botânica até a produção do medicamento fitoterápico (ANTONIO GD, et al., 2013). O conhecimento relacionado a essa prática tem sempre acompanhado a evolução do homem através das gerações e cada povo aprofunda esse conhecimento através do exemplo de seus familiares (CAMARGO S e PEREIRA VBL, 2013). O uso de medicamentos de origem sintética, mostra-se amplo em países desenvolvidos (SOUZAMOREIRA TM, et al., 2010).

Contudo, estudos mostram que, entre os principais motivos para as plantas medicinais serem usadas como alternativa para o cuidado com a saúde, estão a falta de acesso aos medicamentos sintéticos, a tradição do uso de plantas com fins medicinais, a condição de pobreza e o fácil cultivo em casa, fazendo com que 0 indivíduo volte a se conectar com a natureza (VEIGA JVF e PINTO AC, 2005). Medicamentos procedentes de fitoterápicos tem menos chance de causar efeitos colaterais e são mais ativos que os medicamentos alopáticos (FRANCISCO KSF, 2010).

A Agência Nacional de Vigilância Sanitária (ANVISA) é o principal órgão responsável pela regulamentação de plantas medicinais e fitoterápicos no Brasil. Para garantia de segurança e eficácia devem ser aplicadas metodologias químicas, botânicas, controle de qualidade microbiológica, análise de fraudes e contaminação por microrganismos que podem propiciar a degradação do material vegetal, diminuindo a sua eficácia e segurança (SOUZA-MOREIRA TM, et al., 2010).

O uso de plantas medicinais sem acompanhamento, guiada pela mídia e associada aos fármacos, aumentam o risco de morbimortalidade causados pelos efeitos adversos, interações alimentares, interações medicamentosas e toxicidade provocada por estes produtos. Pessoas que comercializam plantas medicinais sem os critérios de adequação à saúde, segurança e eficácia exigidos nos produtos pela ANVISA, obtêm os conhecimentos geralmente advindos da tradição oral, sem o adequado respaldo científico, ameaçando a qualidade de vida de seus compradores (SANTOS RL, et al., 2011).

O uso de plantas medicinais e fitoterápicos deve ser aplicado em indivíduos saudáveis para fins preventivos ou em casos patológicos leves, pois casos mais complexos ou de maior gravidade exigem uma abordagem multidisciplinar e acompanhamento profissional (GONÇALVES JS, 2019). No entanto, os tratamentos medicinais de origem vegetal são utilizados no Brasil de forma errônea, em destaque por aqueles que estão fazendo uso de outros medicamentos (SANTOS RL, et al., 2011). Grande parte dos entrevistados, em um estudo realizado em 2002, afirmou que faz uso das plantas medicinais acreditando que não apresentam malefícios à saúde e a primeira atitude é recorrer aos chás e xaropes (AMOROZO MCM, 2002). 
Instituições com um olhar voltado para as plantas medicinais disponibilizam ações relacionadas para o saber popular e fitoterápico. De acordo com estudos, a Pastoral da Saúde, vinculada à Igreja Católica, atua em plantas medicinais e fitoterápicos, resgatando o saber popular na produção de fitoterápicos disponibilizados à população (ARAUJO RCZ e CRESPO AM, 2018).

Em 2019, o mundo deparou-se com uma doença sem protocolos específicos para o atendimento. A Organização Mundial da Saúde (OMS) declarou que o surto de SARS-CoV-2 (vírus causador da doença COVID-19) é uma emergência de saúde pública de interesse internacional. Diferente do surto de SARS, causado pelo SARS-CoV, em 2003, o SARS-CoV-2 tem maior capacidade de transmissão com manifestações clínicas dominadas por sintomas respiratórios e danos cardiovasculares (HUANG C, et al., 2020; TURNER AJ, et al., 2004). Ao se deparar com o desconhecido, a utilização de chás, por parte da população, pode ocasionar efeitos colaterais e reações concomitantes com medicamentos e alimentos (SANTOS RL, et al., 2011).

Assim, o presente artigo de pesquisa objetivou avaliar o conhecimento e uso de plantas medicinais e fitoterápicos como recurso terapêutico complementar em adultos participantes da pastoral da saúde de uma cidade do Paraná e verificar alterações de consumo relacionados ao isolamento social recomendado pela OMS, a fim de frear o contágio do vírus SARS-CoV-2 (causador da doença COVID-19).

\section{MÉTODOS}

Trata-se de um estudo observacional-exploratório, como instrumento de coleta de dados quali e quantitativo organizado no formato de um roteiro de entrevista semiestruturada. Foi utilizada pesquisa qualitativa em decorrência de os resultados serem observados por meio de avaliação das respostas apresentadas pelos participantes em um grupo de rede social em uma cidade do Paraná. Quanto aos procedimentos técnicos, o estudo foi realizado em duas etapas: a primeira, através de uma revisão teórica, e a segunda composta pela pesquisa de campo. Quanto ao desenvolvimento no tempo, a pesquisa se caracteriza como seccional, sendo executada no final do segundo semestre de 2020 . O presente estudo teve a participação de 10 adultos, com amostra não probabilística, de escolha intencional, entre participantes da pastoral da saúde de uma cidade do Paraná. A captação dos participantes se deu por convite contendo uma breve descrição do estudo e a quantidade de participantes foi definida pelo critério de saturação.

Ao realizar a amostra por saturação, pode-se avaliar uma redundância ou repetição e decidiu-se por não persistir na coleta, pois as informações pelos novos participantes não acrescentariam às já observadas. Todavia, o método de saturação é uma ferramenta influenciada por fenômenos cognitivos e afetivos dos participantes, consequentemente o ponto de saturação está sujeito a imprecisões (FONTANELLA BJB, et al., 2008), por isso, foi determinado um número aproximado de 20 amostras, obedecendo ao protocolo do comitê de ética, com aprovação pelo parecer consubstanciado número 4.275.818. A coleta de dados foi seguindo um roteiro de entrevista, composto por questões fechadas, para traçar o perfil dos informantes, e outras cinco questões abertas, permitindo a captação dos saberes e práticas em relação ao uso de plantas medicinais e fitoterápicos (BADKE MR, 2008).

Outro instrumento, abordando conhecimentos sobre a COVID-19, foi adaptado de Lima DLF, et al. (2020), visando compreender as crenças a respeito da pandemia e, posteriormente, relacionar com o consumo de plantas medicinais. Os participantes foram recrutados aleatoriamente através de mídias sociais, Facebook, com o link: www.pastoraldasaudefoz.com, analisandos e o perfil do participante atendia aos critérios de inclusão e exclusão de participação da pesquisa. Dentro dos critérios exigidos, os participantes assinaram o Termo de Consentimento Livre Esclarecido (TCLE), assim como permissão para o uso das gravações da entrevista através do registro em áudio. A entrevista se deu por meio de vídeo chamadas ou contato telefônico - a critério do participante. O método de realização da pesquisa foi escolhido para evitar ao máximo qualquer forma de contato físico, respeitando o recomendado pela OMS para evitar disseminação do vírus SARS-CoV2 (BRASIL, 2020a).

Somente foram inclusos na pesquisa os adultos participantes da pastoral da saúde de uma cidade do Paraná, naturais da região ou residentes há mais de 10 anos no local, com idade entre 30 e 60 anos, submetidos ao isolamento social aconselhado pela OMS, e que concordaram com os critérios da execução da pesquisa. Os critérios de exclusão da investigação foram indivíduos com qualquer tipo de deficiência comunicativa que impossibilitasse a interação via conferência no computador ou contato telefônico. 
Para a coleta de dados foram utilizados computador com conexão à internet e celular com gravador. A entrevista foi do tipo observador-como-participante, modalidade de observação usada como estratégia nas relações, um roteiro de observação e um diário de campo para registro de informações não formais que possam surgir. Quanto ao método de saturação, a pesquisa seguiu os seguintes passos: registro de dados brutos; imersão em cada registro; compilação e análises individuais; união dos temas ou enunciados para cada categoria ou nova categoria; codificação dos dados; alocação em tabela dos temas e enunciados; constatação da saturação teórica para cada categoria (FONTANELLA BJB, 2011).

A transcrição dos áudios se deu por preparação: esquema de transcrição do tipo tabelar e naturalista; conhecimento: familiarização das informações e identificação de pistas que podem estar escondidas sem o conhecimento do entrevistado devido às variedades e particularidades discursivas; escrita: transcrição completa; edição: etapa de maior atenção, pois pontuações podem alterar o sentido do texto e sentimentos; revisão: leitura das transcrições, reescuta dos áudios e comparação da transcrição com notas que possam existir; finalização: armazenamento dos áudios e transcrições (FONTANELLA BJB, 2011).

Para o tratamento dos dados foi utilizado o método de Minayo MCS (1992), intitulado análise de conteúdo, que se aprofunda nos significados, nas essências, relações humanas, nas atitudes, crenças e valores. Com essa técnica é possível fazer uma análise mais profunda dos significados das falas dos participantes, dividindo-se em quatro etapas: aprontar e uniformizar as informações que serão estudadas; unir os dados de maneira que as divisões feitas representem o conteúdo a ser analisado; agrupar as informações de acordo com os critérios: semântico, sintático, léxico e expressivo; analisar os dados levando em consideração os objetivos da pesquisa.

\section{RESULTADOS}

\section{Caraterização dos entrevistados}

Fizeram parte dessa pesquisa dez indivíduos, sendo oito mulheres e dois homens. Quanto à idade dos entrevistados, constata-se variação de 32 a 60 anos. No que se refere a ocupação, observa-se grande parte de aposentados, desempregados ou realizando atividades online devido ao isolamento social aconselhado pela OMS. No entanto, a renda mensal apresentada está entre um a três salários mínimos $(R \$ 1.045)$, valor de acordo com a lei no 14.013, de 10 de junho de 2020 (BRASIL, 2020b). Quanto à escolaridade, observa-se que a maioria dos entrevistados possui ensino médio completo.

\section{Origem das práticas}

Através das entrevistas, pode-se verificar saturação significativa de como o indivíduo foi apresentado ao uso de plantas medicinais, através do exemplo familiar com a mãe, conforme os desconfortos e doenças foram aparecendo durante seu crescimento.

"... a minha filha está com uma dorzinha de barriga, eu faço um chazinho ali com ela: "filha, vamos lá na cozinha fazer um chazinho? A mamãe faz um chazinho para você." Parece que aquele aconchego, aquele carinho, aquele negócio assim de você ir lá fazer um chá para o teu filho, fazer um chá para alguém, parece assim, que é mais afeto, parece que vai te curar e amenizar a tua dor. As vezes nem é tão eficaz (a planta), mas ali, aquele aconchego "vamos fazer um chazinho, tomar morninho, vamos tomar?" Parece que é tão mais gostoso. As vezes até dou um remédio de farmácia para ela, junto (chá e medicamento), mas eu dou um chazinho também." (GP)

Apenas um participante relata ter aprendido a utilizar os fitoterápicos através do convívio social e práticas entre amigos e/ou através de conversas que surgiram entre estranhos, decidindo, assim, testar suas propriedades sozinho e, posteriormente, tomou como hábito. Ao analisar os hábitos de tal participante e comparar com os outros, nota-se um desinteresse em replicar o conhecimento empírico.

Quando questionado sobre qual a última vez que utilizaram alguma planta medicinal para tratar a si ou um familiar, foram observadas catorze plantas expostas na (Quadro 1) com nome popular, suas indicações de acordo com o participante e nome científico acompanhado das indicações científicas comprovadas em estudos. 


\section{Revista Eletrônica Acervo Saúde / Electronic Journal Collection Health | ISSN 2178-2091}

Quadro 1 - Tipos de plantas: uso popular e uso científico.

\begin{tabular}{|c|c|c|c|}
\hline Nome popular & Indicação popular & Nome científico & Indicação científica \\
\hline Gengibre & $\begin{array}{ll}\text { - } & \text { Tosse } \\
\text { - } & \text { Gripe }\end{array}$ & Zingiber officinale Roscoe. & $\begin{array}{l}\text { - Broncoespasmos } \\
\text { - Aosses produtivas } \\
\text { - Infecções das vias aéreas superiores } \\
\text { - Dispepsias } \\
\text { - Labirintose } \\
\text { - Zumbidos }\end{array}$ \\
\hline Tanchagem & $\begin{array}{l}\text { - Intestino } \\
\text { - Anti-inflamatório }\end{array}$ & Plantago major L. & $\begin{array}{ll} & \text { Antiinflamatório } \\
\text { - } & \text { Antisséptico da cavidade oral } \\
\text { - } & \text { Laxativa } \\
\text { - } & \text { Hipolipemiante } \\
\text { Cicatrizante }\end{array}$ \\
\hline Goiabeira & Estômago & Psidium guajava $L$. & $\begin{array}{l}\text { Tratamento da diarreia aguda não infecciosa e enterite por } \\
\text { rotavírus. }\end{array}$ \\
\hline Marcela & Estômago & Achyrocline satureioides & $\begin{array}{l}\text { - } \quad \text { Processos inflamatórios, alérgicos ou infecciosos } \\
\text { das vias aéreas superiores } \\
\text { - } \quad \text { Refluxo gastroesofágico }\end{array}$ \\
\hline Boldo & $\begin{array}{ll}\text { - } & \text { Dormir melhor } \\
\text { - } & \text { Dor de cabeça } \\
\text { - } & \text { Estômago } \\
\text { - } & \text { Fígado } \\
\end{array}$ & Plectranthus barbatus Andrews & - Antidispéptico \\
\hline Hortelã & $\begin{array}{ll}\text { - } & \text { Verme } \\
\text { - } & \text { Digestivo }\end{array}$ & Mentha $\times$ piperita $L$. & $\begin{array}{ll}\text { - } & \text { Cólicas digestivas } \\
\text { - } & \text { Má digestão } \\
\text { - } & \text { Flatulência } \\
\text { - } & \text { Antisséptica }\end{array}$ \\
\hline Orégano & $\begin{array}{l}\text { - } \quad \text { Estômago } \\
\text { - } \quad \text { Mal estar }\end{array}$ & Origanum vulgare $L$ & $\begin{array}{ll}\text { - } & \text { Gripes e resfriados } \\
\text { - } & \text { Indigestão } \\
\text { - } & \text { Flatulência } \\
\text { - } & \text { Distúrbios estomacais e cólicas menstruais } \\
\text { - } & \text { Dores articulares e musculares } \\
\text { - } & \text { Dor de dente } \\
\text { - } & \text { Cefaleias }\end{array}$ \\
\hline
\end{tabular}


Revista Eletrônica Acervo Saúde / Electronic Journal Collection Health | ISSN 2178-2091

\begin{tabular}{|c|c|c|c|}
\hline Nome popular & Indicação popular & Nome científico & Indicação científica \\
\hline Carqueja & Estômago & Baccharis trimera (Less.) DC. & $\begin{array}{l}\text { - Dispepsias biliares e dores ciática } \\
\text { - Lombar e na coluna } \\
\text { - Diurética } \\
\text { - Antimicrobiano } \\
\text { - Antioxidante }\end{array}$ \\
\hline Camomila & $\begin{array}{ll}\text { - } & \text { Calmante } \\
\text { - } & \text { Estômago }\end{array}$ & Matricaria chamomilla $L$. & $\begin{array}{l}\text { - } \quad \text { Antiespasmódico } \\
\text { - Ansiolítico e sedativo leve } \\
\text { - } \quad \text { Antiinflamatório em afecções da cavidade oral }\end{array}$ \\
\hline Guaco & $\begin{array}{ll}- & \text { Tosse } \\
- & \text { Gripe }\end{array}$ & Mikania glomerata Spreng. & $\begin{array}{l}\text { - Tosses produtivas } \\
\text { - Asma }\end{array}$ \\
\hline Capim cidreira & $\begin{array}{l}\text { - } \quad \text { Calmante } \\
\text { - Gripe }\end{array}$ & Cymbopogon citratus (DC.) Stapf & $\begin{array}{ll}\text { - } & \text { Ansiedade leve } \\
\text { - } & \text { Cefaleias } \\
\text { - } & \text { Cólicas intestinais } \\
\text { - } & \text { Expectorante } \\
\text { - } & \text { Antiespasmódico } \\
\end{array}$ \\
\hline Alecrim & $\begin{array}{l}\text { - Dor de cabeça } \\
\text { - Estômago }\end{array}$ & Rosmarinus officinalis $L$. & $\begin{array}{ll}\text { - } & \text { Hipertensão arterial leve } \\
\text { - } & \text { Insuficiência cardíaca leve } \\
\text { - } & \text { Flatulência } \\
\text { - } & \text { Antiespasmódico } \\
\text { - } & \text { Antioxidante } \\
\text { - } & \text { Antiinflamatório } \\
\text { - } & \text { Analgésico }\end{array}$ \\
\hline Alfavaca & $\begin{array}{ll}\text { - } & \text { Calmante } \\
\text { - } & \text { Dormir melhor }\end{array}$ & Ocimum canum $L$. & $\begin{array}{ll}\text { - } & \text { Afecções da cavidade oral } \\
\text { - } & \text { Exerce atividades cardiovasculares } \\
\text { - } & \text { Infecções intestinais e dos rins } \\
\text { - } & \text { Insônia } \\
\text { - } & \text { Câimbra } \\
\text { - } & \text { Cólica } \\
\text { - } & \text { Dispepsia } \\
\text { - } & \text { Dor de cabeça nervosa } \\
\text { - } & \text { Febre } \\
\text { - } & \text { Flatulência } \\
\text { - } & \text { Fraqueza } \\
\text { - } & \text { Reumatismo } \\
\text { - } & \text { Vômito }\end{array}$ \\
\hline Erva-doce & $\begin{array}{ll}\text { - } & \text { Calmante } \\
\text { - Gases } \\
\end{array}$ & Pimpinella anisum & $\begin{array}{ll}- & \text { Antidispéptico } \\
\text { - } & \text { Antiespasmódico } \\
\end{array}$ \\
\hline
\end{tabular}

Fonte: OLIVEIRA JG, et al., 2021. Dados extraídos de BRASIL, 2011; BRASIL, 2016; PEREIRA MAS, et al., 2017; BRASIL, 2018; SOUZA SP, et al., 2012; ALONSO JR, 2016; PANIZZA ST, et al., 2012. 
Observa-se que somente cinco dos relatos apresentados é utilizado com indicação terapêutica comprovada cientificamente diferente de seu conhecimento popular.

\section{Formas de utilização}

Os participantes que cultivam algumas espécies de plantas medicinais relatam colhê-la no momento do preparo do chá, preferencialmente a noite. No entanto, devido possuir um espaço físico limitado, muitas plantas são adquiridas no mercado ou farmácia. Grande parte dos entrevistados se preocupa com a higienização das plantas antes de preparar o chá, no entanto ao serem questionados, todos afirmaram apenas realizar uma breve lavagem em água corrente, não garantindo estar bem protegido contra sujidades que possam tê-las contaminado. "...Só passo na água. Só para tirar o cocô do passarinho e pronto (risos)." (GFFO)

Alguns participantes mencionam a importância de se atentar à data de validade das plantas comercializadas, no entanto, afirmam não possuir o hábito de observar quaisquer inconformidades como mofo antes de preparar o chá. “.... Eu jogo direto na água. Não higienizo, não! Porque eu acho que se a planta tá empacotada, ela já está higienizada." (RGO). Foi observada a prevalência de infusão como método de preparo.

\section{Remédios de farmácia}

Ao serem questionados sobre remédios de farmácia e plantas medicinais, grande parte do grupo afirma que o remédio de farmácia age mais rápido, porém, para uma única patologia.

“... O efeito dele é bem mais rápido (remédio de farmácia), né. Você já está comprando específico pra alguma coisa que você está sentindo no momento. As plantas... você tem que fazer mais uso para ela fazer mais efeito..." (RGS)

“...Remédios (plantas) medicinais, na minha opinião, eu sei que eles funcionam. Demora um pouco. As vezes dependendo (da enfermidade), precisa de um tratamento mais prolongado, mas dá resultado! O da farmácia, aparentemente parece que é mais rápido..." (AR)

Segundo um dos entrevistados, o uso de remédio de farmácia não funciona, porque a doença retorna depois de algum tempo, observada no relato abaixo:

“...Quando nós éramos crianças, eu lembro que eu nunca tomei antibiótico e a gente (família) não era doente. A minha mãe toda a vida só dava um chazinho pra isso, um chazinho praquilo e a gente não era doente. Então eu acredito muito nesses chás, sabe, porque fazia efeito com a gente, por que não vai fazer efeito com os nossos filhos? Até que um dia, uma vez, eu tinha levado a minha menina na pediatra e ela me deu um antibiótico, pra minha menina, porque ela estava com dor de garganta, né. Aí tá, dei um remédio pra dor de garganta. Tá, que bom, sarou, foi muito bom! Aí, passou mais um tempo, e ela estava de novo com dor de garganta. Aí eu pensei: "Meu Deus, essa menina teve dor de garganta esse ano, já tomou antibiótico, vai tomar de novo?" (GPS)

\section{Chás e o isolamento social}

Ao serem questionados quanto ao comportamento em relação ao uso de plantas medicinais durante a quarentena, aconselhada pela OMS, todos os participantes afirmaram ser indiferentes quanto à mudança de comportamento e não acreditar que os chás possuem alguma atividade contra o COVID-19, no entanto, creem que possa melhorar a imunidade e consequentemente sintomas ocasionados pela gripe comum. Ao serem submetidos a um caso hipotético de exposição ao vírus e atestado positivo, todos os participantes afirmaram fazer uso das plantas dentro de seu conhecimento e aqueles indicados por vizinhos e familiares, independentemente de estar usando medicamento receitado pelo médico.

"... Ah, com certeza, tomaria de tudo! Tomaria Ivermectina, tudo! Tudo o que me dessem eu tomaria, porque tem que fazer alguma coisa, né. De alguma forma tentar prevenir... prevenir não, né, tentar amenizar..." (FRJ) 


\section{DISCUSSÃO}

Observa-se uma prevalência do sexo feminino, tanto em aceitar participar da pesquisa, quanto em se enquadrar nos critérios de participação. Acredita-se que esse perfil seja favorável aos estudos relacionados a plantas medicinais, uma vez que adultos e idosos carregam maior conhecimento acerca das práticas adquiridas no âmbito familiar a longo prazo (CANTER PH e ERNST E, 2004; GAMA MAX e SILVA MJP, 2006; LOYA AM, et al., 2009; MARLIÉRE LDP, et al., 2008; ROSA RL, et al., 2012).

Quanto à origem das práticas, nota-se que a prevalência do sexo feminino reforça o modo de transmissão de saberes, inconscientemente, entre mãe e filhos, através do afeto e cuidado. Assim como Badke MR, et al. (2011) menciona, grande parte da população faz uso de plantas medicinais para cuidar da saúde, tanto própria quanto dos membros familiares. Nota-se que a mulher se torna sobrecarregada através dos valores culturais, passando a assumir a responsabilidade que poderia ser compartilhada (BUDÓ MLD, et.al., 2008).

Quanto aos resultados observados no Quadro 1, nos permite dizer que as práticas sedimentadas pelo saber popular contam com o respaldo científico para aquelas que as propriedades curativas já são conhecidas pela comunidade científica. No entanto, as plantas, como qualquer outra substância farmacológica ativa, alteram os sistemas enzimáticos, transportadores e processos fisiológicos (MOREIRA FV, et al., 2010), podendo interagir com outros medicamentos, causando efeitos colaterais prejudiciais e reduzindo os benefícios esperados com o tratamento convencional (MAMINDLA S, et al., 2016).

No que se refere às plantas cujas propriedades mencionadas nas entrevistas não correspondem às indicações científicas estão: o boldo (Plectranthus barbatus Andrews), a hortelã (Mentha $\times$ piperita L.), a camomila (Matricaria chamomilla L.) e o capim cidreira (Cymbopogon citratus (DC.) Stapf). A primeira é citada com atividade calmante e alívio de dores de cabeça, porém, ao se procurar as indicações científicas, não se encontraram estudos comprovando atividade calmante em espécies, tanto de Plectranthus barbatus quanto de Peumus boldus, sendo indicadas para outras finalidades. Não há estudos comprovando efetividade da hortelã para tratamento de vermes, contudo apresenta atividade antisséptica (GONÇALVES JS, 2019).

A camomila, muito citada pelos participantes pelo seu potencial calmante, pode interagir com medicamentos com varfarina, estatinas e contraceptivos orais, além de ser contra indicada para gestantes, devido à atividade emenagoga e relaxante da musculatura lisa, e em indivíduos com hipersensibilidade ou alergia à planta (BRASIL, 2016; ALONSO JR, 2016), além disso, não encontraram-se dados de sua efetividade em relação ao estômago. Quanto ao capim cidreira, não possui atividade antigripal, no entanto apresenta atividade expectorante, podendo potencializar o efeito de medicamentos sedativos (BRASIL, 2011).

Quanto ao modo de preparo observado, segundo estudos, a infusão é o processo de extração de compostos químicos de plantas, através da imersão em água quente, indicado quando a preparação é feita a partir de partes tenras da planta, como as folhas, as flores e os botões florais (GUIMARÃES R, et al., 2011;CARVALHO AM e MORALES R, 2010). Observa-se que os participantes usam desse mesmo método em raízes, o que não é adequado, pois caules, raízes, frutos secos e partes mais duras da planta necessitam de decocção, isto é, fervura da planta previamente imersa em água (GUIMARÃES R, et al., 2011; CARVALHO AM e MORALES R, 2010). O método errôneo para obtenção da forma farmacêutica pela via oral, resulta em perda e/ou não extração dos princípios ativos (BRASIL, 2010).

Diferente dos medicamentos sintéticos, as plantas podem apresentar constituintes em concentrações diversas que interagem com muitas outras substâncias resultantes do metabolismo primário ou secundário da planta (TANIYA T e NARDEV S, 2016; MOREIRA FV, et al., 2010). As interações entre um princípio ativo e os componentes químicos que estão contidos nas plantas possuem potencial para causar alterações nas concentrações plasmáticas dos medicamentos, comprometendo sua efetividade e segurança (ALEXANDRE RF, et al., 2008).

Através do questionário observa-se que o medo do COVID-19 pode ocasionar comportamentos inadequados quanto ao uso de plantas medicinais, levando à possível toxicidade e interações medicamentosas em pacientes já diagnosticados. No entanto, são necessários mais estudos para comprovação em pacientes infectados pelo vírus SARS-CoV-2. 


\section{CONCLUSÃO}

Constata-se que o uso de plantas medicinais em forma de chás assume grande valor na vida destas pessoas e a maioria dos saberes e das práticas referentes ao uso das plantas medicinais foram adquiridas no ambiente familiar, com a mulher como a principal detentora e difusora desse conhecimento. No entanto, faz-se necessário melhor conhecimento quanto às formas de preparo em plantas tenras para a eficaz extração dos princípios ativos. Pacientes expostos ao vírus causador do COVID-19 podem apresentar comportamento inadequado quanto ao consumo de plantas medicinais induzidos pelo medo, para tanto, é necessário que se realizem estudos voltados aos participantes diagnosticados. Há a necessidade de um maior domínio desse saber pelo profissional nutricionista, a fim de poder esclarecer sobre indicações e contra indicações com o uso de plantas medicinais na saúde dos pacientes. É no contexto de conflitos entre o saber científico e popular que a nutrição assume importância, pois o nutricionista atuará com o saber científico e o popular, tendo em vista ser ele o profissional que trabalha mais diretamente com ingestão alimentar e comportamento no dia a dia.

\section{REFERÊNCIAS}

1. ALONSO JR. Tratado de fitofármacos e nutracêuticos. 1 ed. São Paulo: AC Farmacêutica; 2016. 1124p.

2. ALEXANDRE RF, et al. Interações entre fármacos e medicamentos fitoterápicos à base de ginkgo ou ginseng. Rev. Bras. Farmacogn. 2008; 18(1):117-126.

3. AMOROZO MCM. Uso e diversidade de plantas medicinais em Santo Antônio do Leverger, MT, Brasil. Acta Botanica Brasilica, 2002; 16(2): 189-203.

4. ANTONIO GD, et al. Contributions of medicinal plants to care and health promotion in primary healthcare. Interface (Botucatu), 2013; 17(46): 615-33.

5. ARAUJO RCZ, CRESPO AM. Plantas medicinais e o trabalho da pastoral da saúde de Venda Nova do Imigrante. Congresso Nacional dos Trabalhadores/as da Assistência Técnica Extensão Rural e do Setor Público Agrícola do Brasil, Extensão rural e cidadania, 2018.1-7.

6. BADKE MR, et al. Plantas medicinais: o saber sustentado na prática do cotidiano popular. Escola Anna Nery, 2011; 15(1): 132-139.

7. BADKE MR. Conhecimento popular sobre o uso de plantas medicinais e o cuidado de enfermagem. Universidade Federal de Santa Maria Centro de Ciências da Saúde. Programa de Pós-Graduação em Enfermagem, 2008. 89-90.

8. BRASIL. Farmacopeia Brasileira, vol. 2 / Agência Nacional de Vigilância Sanitária. Brasília: Anvisa, 2010. 808 p., 1v/il.

9. BRASIL. Formulário de Fitoterápicos da Farmacopeia Brasileira. 1. ed. Brasília, DF: Agência Nacional de Vigilância Sanitária (ANVISA), 2011. 23-53.

10. BRASIL. Memento Fitoterápico da Farmacopeia Brasileira. 1a. ed. Brasília: Agência Nacional de Vigilância Sanitária (ANVISA), 2016. 85-110.

11. BRASIL. Formulário de Fitoterápicos da Farmacopeia Brasileira (Primeiro Suplemento) Brasília Agência Nacional de Vigilância Sanitária (ANVISA), 2018. 67p.

12. BRASIL. Folha informativa - COVID-19 (doença causada pelo novo coronavírus). Disponível em: https://www.paho.org/bra/index.php?option=com_content\&view=article\&id=6101:covid19\&ltemid=875. Acesso em: 04 de abril de 2020a.

13. BRASIL. Diário oficial da união. Disponível em: https://www.in.gov.br/en/web/dou/-/lei-n-14.013-de-10-de-junho-de2020-261279533. Acesso em: 12 de out. 2020b.

14. BUDÓ MLD, et al. Qualidade de vida e promoção da saúde na perspectiva dos usuários da estratégia de saúde da família. Online Brazilian Journal of Nursing, 2008; 7(1).

15. CAMARGO S e PEREIRA VBL. A prática da fitoterapia pelo nutricionista: algumas reflexões. Rev. Assoc. Bras. Nutrição, 2013. 2-3.

16. CANTER PH e ERNST E. Herbal supplement use by persons aged over 50 years in Britain: frequently used herbs, concomitant use of herbs, nutritional supplements and prescription drugs, rate of informing doctors and potential for negative interactions. Drugs Aging, 2004; 21(9): 597-605.

17. CARVALHO AM e MORALES R. Persistence of wild food and wild medicinal plant knowledge in a northeastern region of portugal. In: Ethnobotany in the new europe: People, health and wild plant resources. UK: Berghahn Books; 2010. p. 147-172.

18. FRANCISCO KSF. Fitoterapia: uma opção para o tratamento odontológico. Revista Saúde, 2010.

19. FONTANELLA BJB, et al. Amostragem por saturação em pesquisas qualitativas em saúde: contribuições teóricas. Cad. Saúde Pública, Rio de Janeiro, 24(1):17-27, jan, 2008.

20. FONTANELLA BJB, et al. Amostragem em pesquisas qualitativas: proposta de procedimentos para constatar saturação teórica. Cad. Saúde Pública, Rio de Janeiro, 27(2):389-394, fev, 2011.

21. GAMA MAX; SILVA MJP. A utilização da fitoterapia por idosos de um Centro de Saúde em área central da cidade de São Paulo. Saúde Coletiva, 2006; 11(3): 79-84.

22. GONÇALVES JS. Manual de Prescrição de Fitoterápicos pelo Nutricionista. - 1. Ed. - Rio de Janeiro: Atheneu, 2019. $366 \mathrm{p}$. 
23. GUIMARÃES R, et al. Infusions and decoctions of mixed herbs used in folk medicine: Synergism in antioxidant potential. Phyther Res. 2011; 25(8): 1209-1214.

24. HUANG C, et al. Clinical features of patients infected with 2019 novel coronavirus in Wuhan, China. Lancet, 2020; 395: 497-506.

25. LIMA DLF, et al. COVID-19 no Estado do Ceará: Comportamentos e crenças na chegada da pandemia. Ciênc. saúde coletiva vol.25 no.5 Rio de Janeiro May 2020. 5-8.

26. LOYA AM,et al. Prevalence of polypharmacy, polyherbacy, nutritional supplement use and potential product interactions among older adults living on the United States-Mexico border: a descriptive, questionnaire based study. Drugs Aging, 2009; 26(5): 423-436.

27. MAMINDLA S, et al. Herb-drug interactions: an overview of mechanisms and clinical aspects. Int. J. Pharm. Sci. Res. 2016; 7(9): 3576-86.

28. MARLIÉRE LDP, et al. Utilização de fitoterápicos por idosos: resultados de um inquérito domiciliar em Belo Horizonte (MG), Brasil. Revista Brasileira de Farmacognosia,2008; 18(suppl): 754-760.

29. MINAYO MCS. O desafio do conhecimento: pesquisa qualitativa em saúde. São Paulo: Hucitec/ ABRASCO, 1992. P.299-322.

30. MOREIRA FV, et al. Chemical composition and cardiovascular effects induced by the essential oil of Cymbopogon citratus DC. Stapf, Poaceae, in rats. Rev. Bras. Farmacogn. 2010; 20(6):904-909.

31. PANIZZA ST, et al. Uso tradicional de plantas medicinais e fitoterápicos. 1 ed. Conbrafito; 2012. 267p.

32. PEREIRA MAS, et al. Formulário de Preparação Extemporânea: farmácia da natureza - chás medicinais. 1a. ed. São Paulo: Bertolucci, 2017. 270p.

33. ROSA RL, et al. Investigação do uso de plantas medicinais no tratamento de indivíduos com diabetes melito na cidade de Herval D' Oeste - SC. Revista Brasileira de Plantas medicinais, 2012; 14(1): 50-56.

34. SANTOS RL, et al. Análise sobre a fitoterapia como prática integrativa no Sistema Único de Saúde. Rev Bras Plantas Med. 2011;13(4):486-91.

35. SOUZA SP, et al. Seleção de extratos brutos de plantas com atividade antiobesidade. Rev Bras PI Med, 2012; 14(4), 643-648.

36. SOUZA-MOREIRA TM, et al. O Brasil no contexto de controle de qualidade de plantas medicinais. Rev Bras Farmacog. 2010;20(3):435-40.

37. TANIYA T, NARDEV S. A review on sideffects of herbal drugs. World. J. Pharm. Sci. 2016; 5(6):2150-2164.

38. TURNER AJ, et al. ACE2: from vasopeptidase to SARS virus receptor. Trends Pharmacol. Sci. 2004; 25: $291-294$.

39. VEIGA JVF e PINTO AC. Plantas medicinais: cura segura? Química Nova, 2005;28(3):519-528. 